\title{
Türkiye'de Yetişen Helleborus L. Türleri Üzerinde Farmasötik Botanik Yönünden Araştırmalar
}

\author{
Researches on the Turkish Helleborus Species from the Aspect \\ of Pharmaceutical Botany \\ Funda B İ NG ÖL * *
}

\begin{abstract}
ÖZET
$\mathrm{Bu}$ çalışmada Anadolu'nun farklı bölgelerinden toplanmış iki Helleborus türü incelenmiştir.

Helleborus orientalis Lam. (Bolu ve Kastamonu) ve Helleborus vesicarius Aucher. (Adana) morfolojik ve anatomik özelikleri yönünden incelenerek karşılaştırılmıştır. Bu iki türde gövde yaprağı taşıyıp taşımamaları; sepallerin renk ve şekli; foliküllerin büyüklüğü, birleşme mesafesi ve stilusun uzunluğu ile tohumların renk ve büyüklüğü bakımından farklılık tesbit edilmiştir.
\end{abstract}

\section{SUMMARY}

In this research, two Helleborus species collected from the different regions of Anatolia were investigated.

H. orientalis Lam. (from Bolu and Kastamonu) is compared with $H$. vesicarius Aucher. (Adana), from the point of morphological and anatomical properties. As a result of this study, we found out that each of these two species have their own characteristic elements, such as; carrying leaves on stems or not; the colour and the form of the sepals; the size of the follicules and the distance to which they are coherent, the length of the stylus; colour and size of the seeds.

Anahtar Kelimeler: Helleborus orientalis Lam., Helleborus vesicarius Aucher.

Ranunculaceae familyası bitkilerinden olan Helleborus cinsi orta, güney ve doğu Avrupa'dan Kafkasya sınırlarına kadar uzanan geniş bir yayılma alanına sahiptir $(1,2,3)$.

* Farmakognozi Anabilim Dalı, Eczacılık Fakültesi, Ankara Üniversitesi

** Farmakognozi Anabilim Dalı, Eczacılık Fakültesi, Gazi Üniversitesi 
Türkiye'de doğal olarak yetişen iki türü vardır $(4,5,6,7)$. H. orientalis, Kuzey Anadolu'da geniş bir yayılma alanına sahiptir ; orman açıklıklarında ve orman altlarında yetişir. $H$. vesicarius, Güney Anadolu, Amanos dağları, Kahramanmaraş, Gaziantep çevresinde yetişen endemik bir türdür (8).

Drog olarak kullanılan Rhizoma Hellebori nigri bir Avrupa bitkisi olan Helleborus niger'in (Çöpleme, Noel Gülü) rizom ve köklerinden oluşur. Droğun bileşiminde kalp kuvvetlendirici etkiye sahip hellebrin isimli bir heterozit vardır. Kalp hastalıklarında kalbi kuvvetlendirmek için ve diüretik olarak kullanılır. Halk hekimliğinde emetik ve purgatif olarak ta kullanılmaktadir.

Halk arasında Bohça otu, Kara çöpleme, Siyah harbak, Boynuz otu, Danabağırtan, Danakıran gibi bir çok isim alan $H$. orientalis, zehirli bir tür olarak bilinmekte, kökleri Kuzey Anadolu köylerinde, büyükbaş hayvanların bronşit ve benzeri gögüs hastalıklarında kullanılmaktadir $(9,10,11)$.

$H$. orientalis'i konu alan araştırmalar bulunmasına karşın, $H$. vesicarius türü üzerinde şimdiye kadar araştırma yapılmamış olması, bizi bu bitki üzerinde çalışmaya yöneltmiştir. Her iki tür üzerinde çalışmalarımızı, botanik ve kimyasal olmak üzere iki bölümde yürütmeyi planladik. Botanik kısımda, bitkinin morfolojik ve anatomik özelikleri ile tanıtıcı ve ayırıcı karakterleri saptandı. Kimyasal kısımda ise bitkilerin içerdiği etken maddeleri saptamayı ve miktarları hakkında fikir sahibi olmayı amaçladık*.

\section{DENEL KISIM}

\section{Materyal :}

Helleborus orientalis Lam., 1979 yılının mart ayında Bolu; AladağGölcük yolu üzerinde 900 - 1340 m'den ve 1980 yılının nisan ayında Kastamonu; Daday-Cide arası, Ballıdă̆, Sanatoryumu civarı 1200 m'den, Helleborus vesicarius Aucher., ise Adana; Osmaniye-Hasanbeyli arası, Alman-Pınarı Radar yolu üzerinde, $1220 \mathrm{~m}$ 'den topland 1 . $H$. orientalis örneklerinin bir kısmı çiçekli bir kısmı da meyvalıyd1. $H$. vesicarius'un ise çoğunluğu meyvalıydı. Bitki örnekleri Ankara Üniversitesi Eczacılık Fakültesi Herbaryumu'nda (AEF) 10171, 10172, 10173 numaraları ile kayıtlıdir.

* Bitki üzerinde yapılan kimyasal çalışma ayrıca yayınlanacaktır. 
Toplanan bitkiler çiçek, brakte, rozet yaprak, gövde, rizom olmak üzere kısımlarına ayrılarak, bir kısmı gölgede kurutulup değirmende toz edildi, bir kısmı da formol içinde saklandı. Çalışma materyalinin her birinden, hem formoldeki örneklerden alınan kesilerden hem de toz edilmiş numunelerden preparatlar hazırland reaktifi ile karşılaştırmalı olarak incelendi.

\section{Morfolojik Karakterler:}

Çalışma konumuzu teşkil eden her iki türün de rizomları toprak altında yatık durumda, koyu kahve renkli ve 5-10 mm çapındadır. Üzerinde silindir biçiminde, 1-3 mm çapında kökler taşır.

Gövde $60 \mathrm{~cm}$ (H. orientalis) veya daha boylu olabilen (H. vesicarius), silindir şeklinde, yeşil renkli, zor kırılan bir yapı gösterir.

Araştırma konumuzu oluşturan iki Helleborus türünde de, rizomdan çıkan ve sapı hemen hemen gövde kadar uzun olan parçalı bir rozet yaprak bulunmaktadir.

H. orientalis'de başkaca gövde yaprağı bulunmamasına karşılık, H. vesicarius'da gövdenin tabana yakın kısmından çıkan, sapı spatulat bir yaprağ 1 andıran tek bir yaprak daha görülmektedir. Ayrıca her iki türün gövdesinde de, büyüklükleri az çok farklı olan brakteler bulunmaktadir.

İki türün rozet yaprakları ve brakteleri morfolojik bakımdan birbirinden farklıdır (Şekil 1).

H. vesicarius'da. gövdenin tabanından yükselen yaprağın (gövde yaprağ 1 ) tripartit laminası tabanda genişleyerek bir şerit halinde uzar. Okreayı andıran bu bölge ince ve zarımsı bir yapıdadır. Folioller birbirine çok benzer, şekilleri lanseolattan dar eliptiğe kadar değişebilir. Brakteler de rozet ve gövde yaprağında olduğu gibi pennat loblu tripartit şekildedir (Şekil 2b). Yaprakların hepsi tüysüzdür. $H$. orientalis'de gövde yapraksızdır. Rozet yapraklar tek, uzun saplı, pedat, 7-10 dar eliptik loblu, parçalar geniş dişlidir (Şekil 2a). Yaprakların alt yüzünde tüyler bulunur.

$\mathrm{Bu}$ iki Helleborus türünde periantm dış halkası (kaliks) renk, şekil ve büyüklük bakımından farklı sepallerden meydana gelmiştir.

$H$. vesicarius'da sepaller yeşilimsi-sarı tepeye doğru eflatun renkte 16-18 mm uzunlukta flabelliformdur; $H$. orientalis'de ise yeşilimsi-be- 


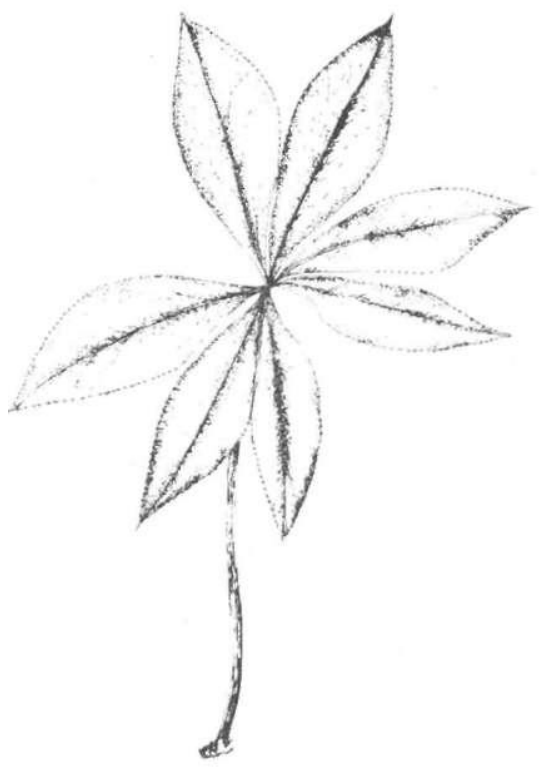

a

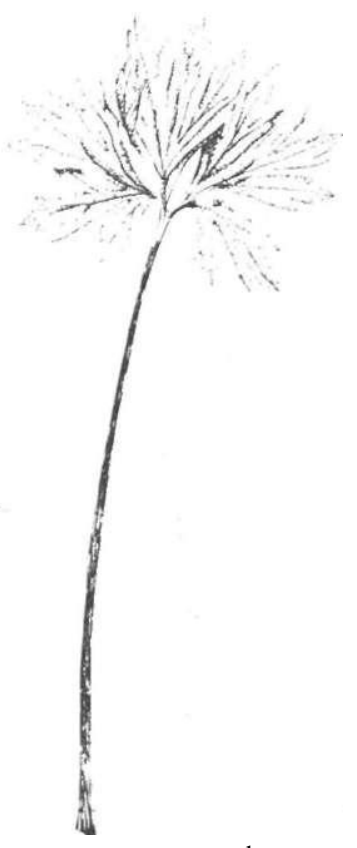

b

Şekil 1: Rozet yaprak (x 1/5). a) H. orientalis, b) H. vesicarius

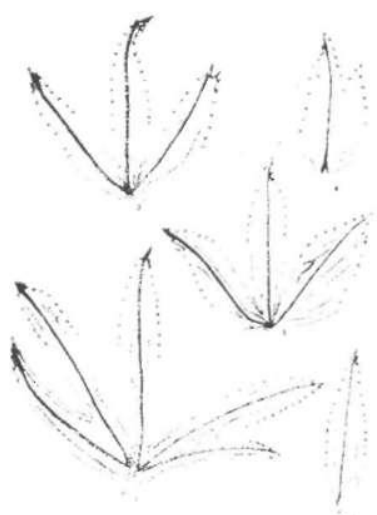

a

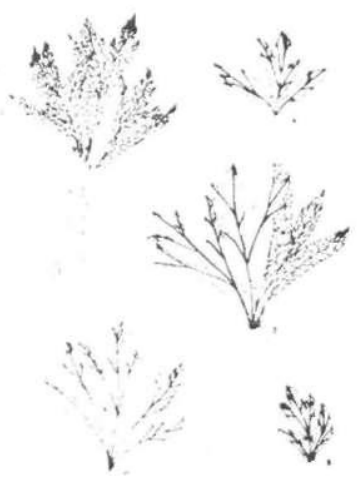

b

Şekil2: Yaprak tipleri (x 1/4): a) H. orientalis 1,2,3,4,5 çok parçalı yapraktan basit yaprağa kadar brakte tipleri; b) $H$. vesicarius 1 . gövde yaprağ $1,2,3,4,5$ brakte tipleri.

yaz renkte rombik, hafif tırnaklı 20-35 mm uzunluktadır. Her ikisinde de çiçekler aktinomorftur. Çiçek halkaları sarmal dizilişte çiçekler hipogindir (Şekil 3). 

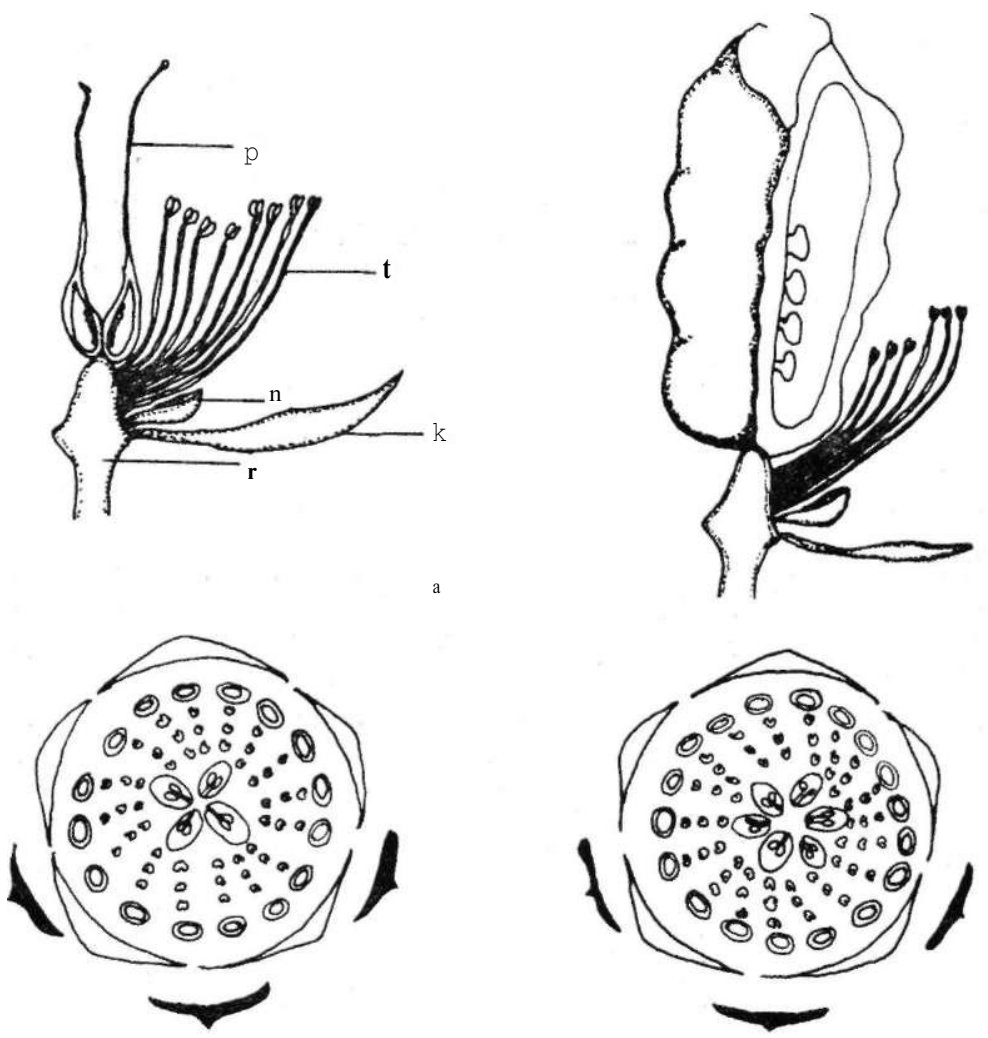
a. $K_{5} C_{16-20} A_{\infty} G_{4}$
c
a. $\mathrm{K}_{5} \mathrm{C}_{16-20} \mathrm{~A}_{\infty} \mathrm{G}_{6}$
d

Şekil 3: Çiçekten boyuna kesi (a- H. orientalis, b- H. veskarius) ve diyagram (c- H. orientalis, d- H.vesicarius) k- sepal, n- nektaryum, p- pistil, r- reseptakulum, s-stamen

Periantın iç halkasını oluşturan çok sayıda (16-20) nektaryum küçük, tubular (huni şeklinde), iki dudaklı ve parçalıdır. Dipte koyu renkli nektar bezi taşır.

Stamenler spiral dizilişli ve çok sayıdadır. Çiçek eksenine göre dışa doğru yönelmiştir, ekstrors anter taşır.

Meyva bir kaç tohumlu folikül topluluğudur, tek karpelli (apokarp) olup karpelin dikişi boyunca açılır. 
Plasentalanma marginaldir, yani ovüller karpellerin kenarına bağlıdır. $H$. vesicarius'da foliküller ortaya yakın bir yere kadar bitişik, basık, 50-70 x 25-32 mm, tohumlar 3-6 adet ve 5-6 mm dir. H. orientalis'de ise foliküller sadece tabanda bitişik, daha küçük, basık değil, 20-25 x 8-12 mm, gagalı, tohumlar genellikle 6 dan fazla ve 2-3 mm dir. Her iki türün meyvasında da stilus kalıcıdır fakat uzunlukları farklıdır. $H$. orientalis'de 10-13 $\mathrm{mm}, H$. vesicarius" ${ }^{n} \mathrm{da} 5-8 \mathrm{~mm}$ kadardır.

\section{Anatomik Karakterler:}

$H$. vesicarius ve $H$. orientalis türleri çiçek, brakte, rozet yaprak, gövde ve rizom olmak üzere kısımlarına ayrılarak anatomik karakterleri incelenmiştir. Hem örneklerden alınan kesilerden hem de toz edilmiş numunelerden Sartur reaktifi ile preparatlar hazırlanmış ve mikroskobik analizleri yapılmıştır.

Rizomdan enine kesi alındı̆̆ında çok geniş bir mantar tabakası ile çevrelendiği görülür. Kabuk parankiması, at nalı şeklinde hilumları olan nişasta taneleri ve yağ damlacıkları içerir (Şekil 4). İletim demetlerini sklerankima bir kep gibi çevreler. Birbirini izleyen odun boruları ve sklerankima demetlerinin tabaka tabaka dizili oluşu, rizomun çok yıllık olduğuna işarettir. Odun borularının çeperleri helezonlu ve skalariform-retikulat kalınlaşma gösterir (Şekil 4).
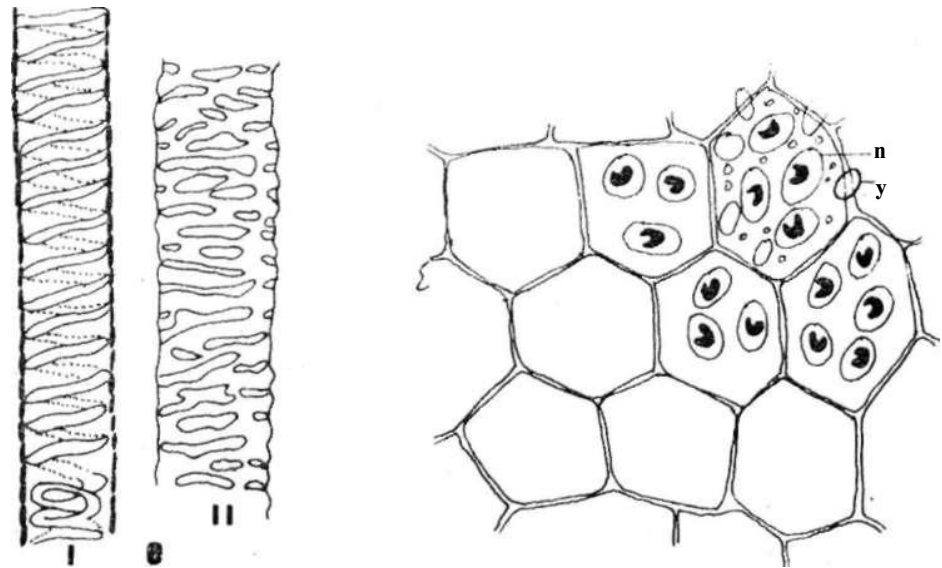

Şekil 4: H. vesicarius Rizom, toz numune (x 600) a) parankimatik doku b) I. helezonlu, II. skalariform-retikulat odun boruları, n- nişasta, y- yă̆.

Gövdeden alınan enine kesilerde bir daire üzerine dizilmiş, irili ufaklı kümeler halinde açık kollateral iletim doku demetleri görülür (Şekil 5). 


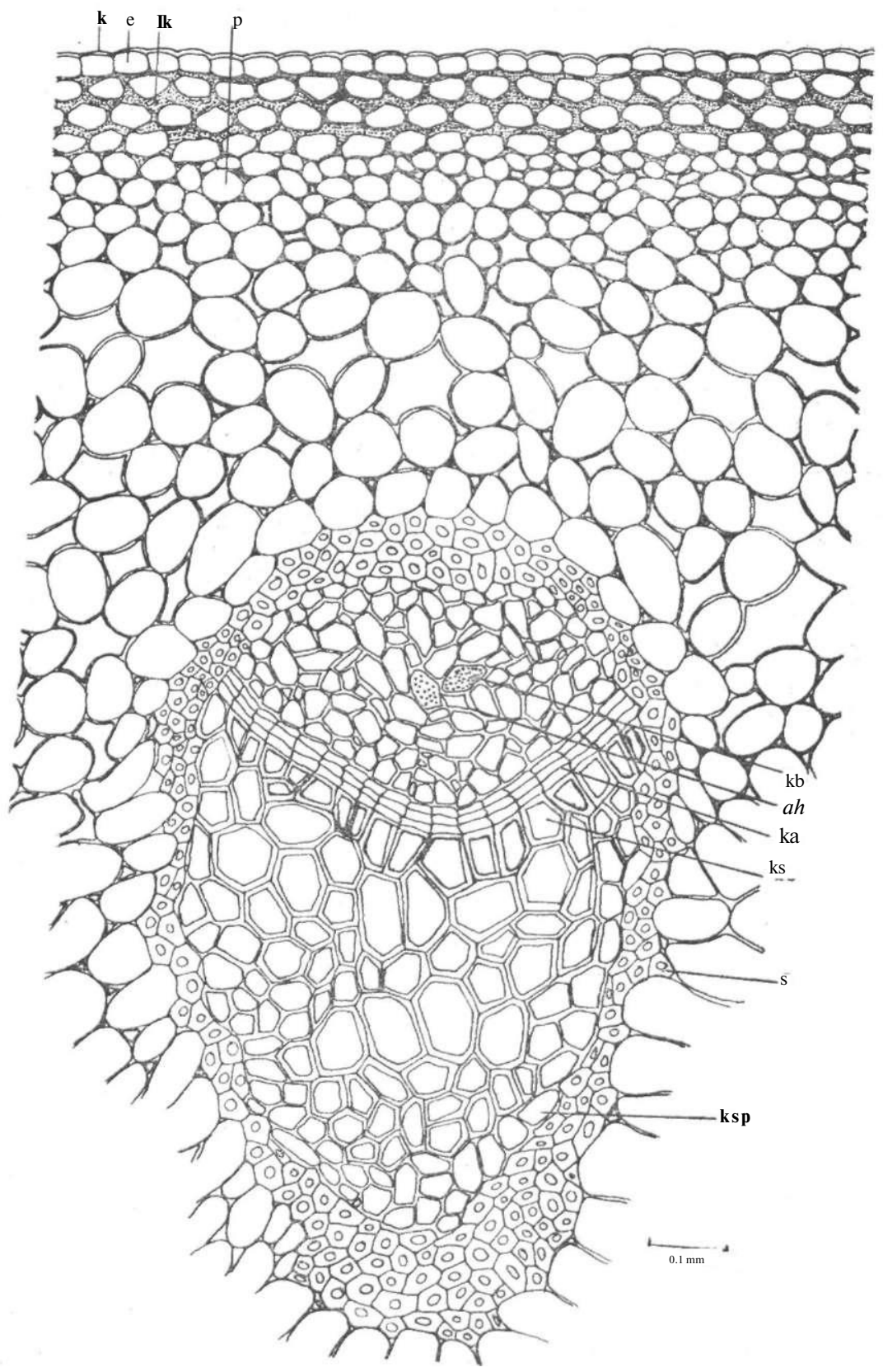

Şekil 5: vesicarius, gövdeden enine keşide açık kollateral iletim demeti k- kutikula, e- epiderma, lk- levha kollenkiması, p-parenkima, kb-kalburlu borular, ah-arkadaş hücreleri ka- kambiyum, ks- ksilem, s- sklerenkima, ksp- ksilem parenkiması. 
Yapraklar anatomik olarak incelendiğinde alt epidermada Helleborus (Ranunculaceae) tipi stomalar görülür. İtletim demetlerini sklerenkima hücreleri çevreler (Şekil 6).

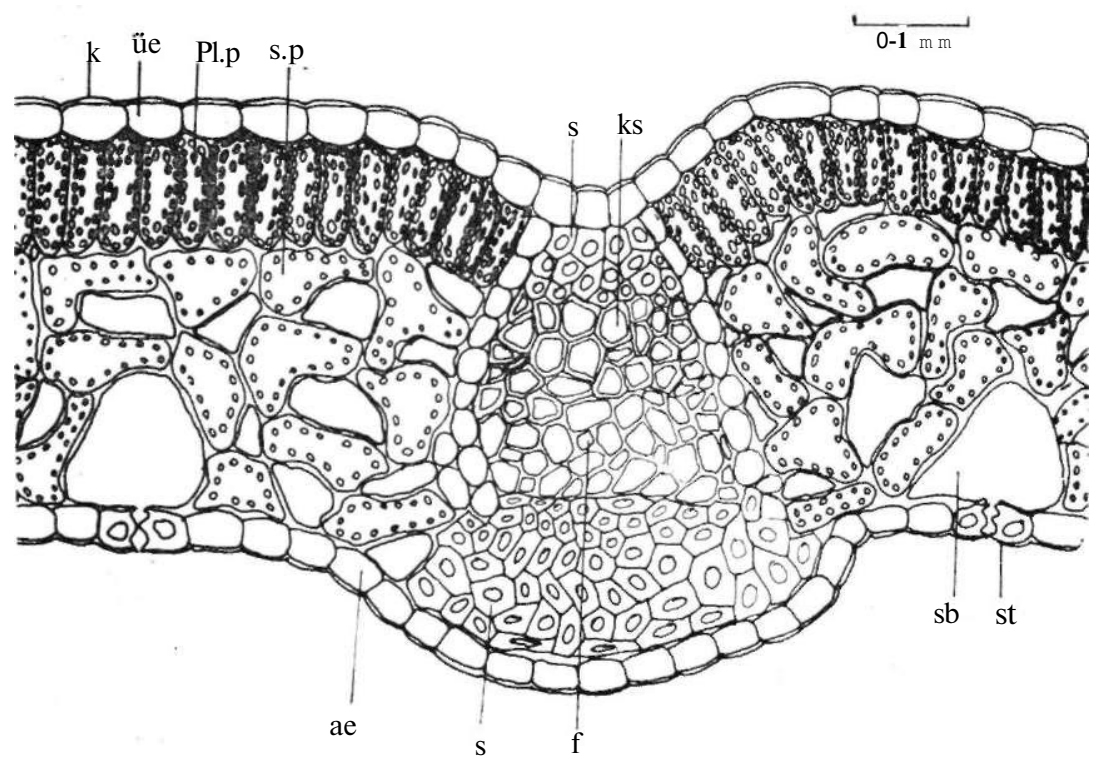

Şekil 6: $H$, vesicarius yapraktan enine kesik- kutikula, üe- üst epiderma, pl-p- palizat parenkiması, s-p- sünger parenkiması, s- sklerenkima, ks- ksilem, ae- alt epiderma, f-floem, sb- solunum boşluğu, st- stoma.

H. orientalis yapraklarının alt yüzünde $H$. vesicarius'dan farklı olarak bacilliform tüyler bulunur (Şekil 7).

Korolladan yüzeysel kesi alındı̆̆ında yuvarlak hücre arası boşluklar taşıyan mezofil doku, toz numunede ise polen taneleri karakteristiktir (Şekil 8).

Meyvadan hazırlanan preparatlarda ekzokarp, mezokarp ve endokarpa ait parçalar görülür. Taş hücreleri yoktur.

Semenden hazırlanan toz numunede ise testa epiderması, yağ damlaları taşıyan besi doku ve endosperma görülür (Şekil 9). 


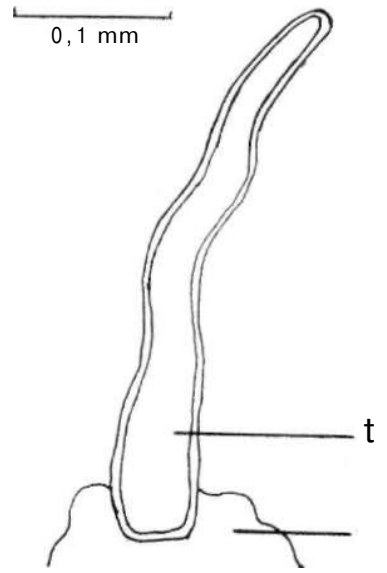

Şekil 7: H. orientalis bacilliform tüy

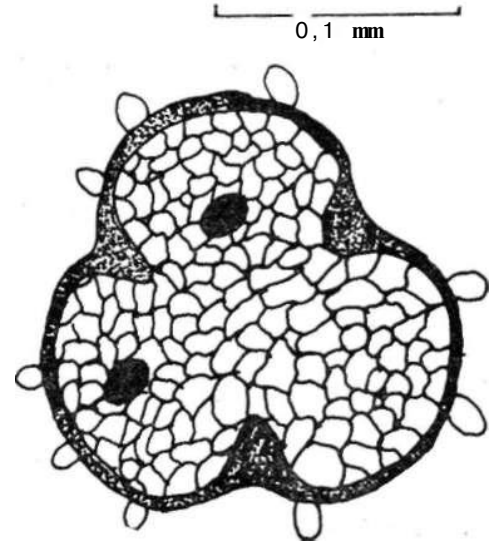

Şekil 8: H. vesicarius (korolla), toz numunede polen

\section{SONUÇ VE TARTIŞMA}

$H$. orientalis ile $H$. vesicarius morfolojik özelikleri ile birbirinden kolayca ayrılabilir. Ancak anatomik özelikleri ile ayırmak kabil değildir. Her iki bitkinin tüm kısımları dokuların çeşidi ve dizilişleri yönünden birbirine çok benzemektedir. Yalnız mikroskobik incelemelerimize göre bacilliform tüyler, $H$. orientalis yapraklarının alt yüzünde bulunmuş fakat $H$. vesicarius'da görülmemiştir. 


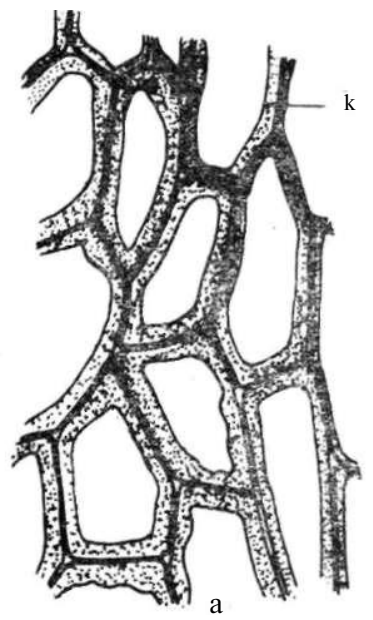

Şekil 9: $H$. veskarilus Semen tozu
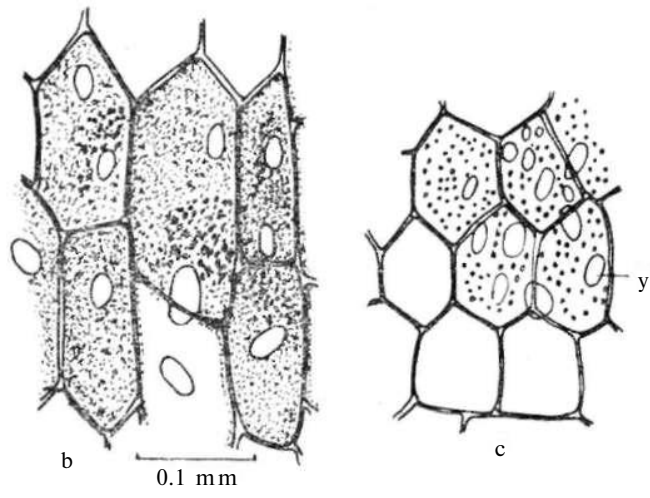

Morfolojik özelikleri yönünden saptanan farklar şunlardır:

H. orientalis'de: Yaprak - bütün yapraklar rozet yaprak

- pedat (parçalı) pedatisekt

- ince, uzun bacilliform tüyler var

Çiçek - Sepal romboidal, yeşil-sarı, 20-35 mm

Foliküller - yanlardan basık değil, 20-25x8-12 mm

- sadece tabanda bitişik, stilus kalıc1, 10-13 $\mathrm{m} \mathrm{m}$

Tohum - 2-3 $\mathrm{mm}$, kahverengi, 6 taneden fazla

H. vesicarius'da: Yaprak - hem rozet hem de gövdenin alt kismında gövde yaprakları var

- rozet yapraklar tripartitus

- tüy yok

Çiçek - Sepal flabelliform, yeşil-sarı, tepede eflatun-kahverengi, $16-18 \mathrm{~mm}$

Foliküller - yanlardan basık, 50-70x25-32 mm

- ortaya kadar birleşik

- stilus kalic1, 5-8 $\mathrm{mm}$

Tohum - 5-6 mm, sar1, 3-6 tane 

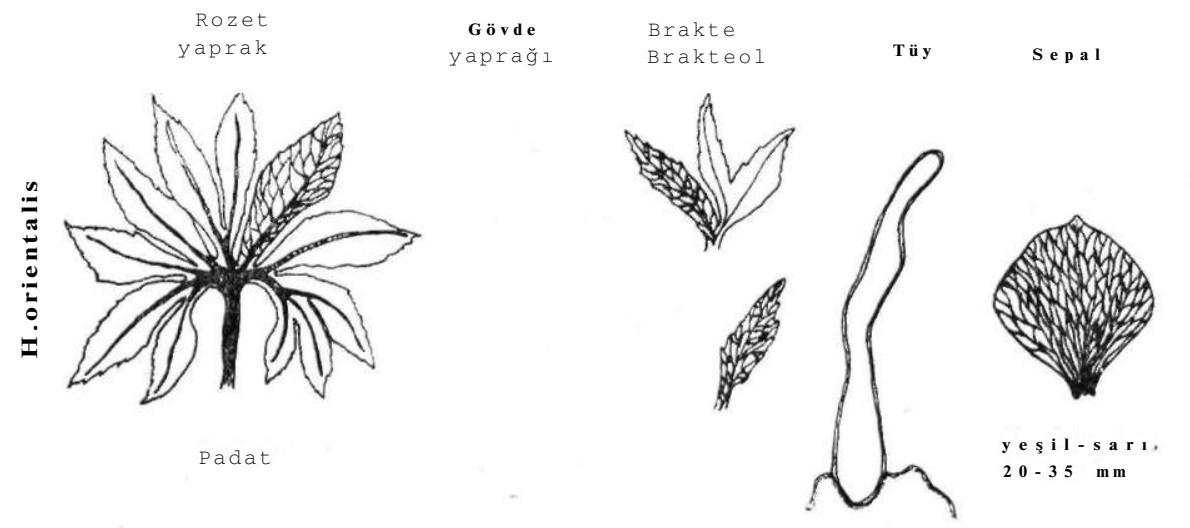

Foliküiller

To h u m

Padat

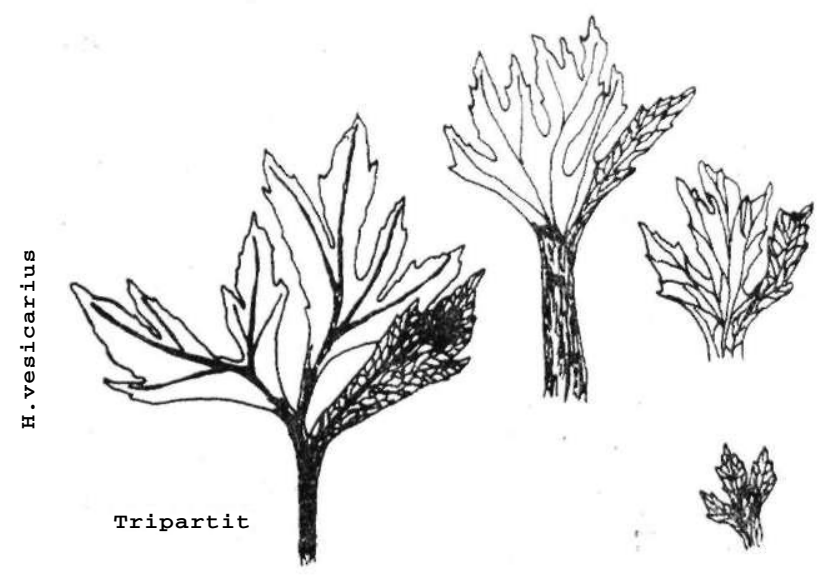

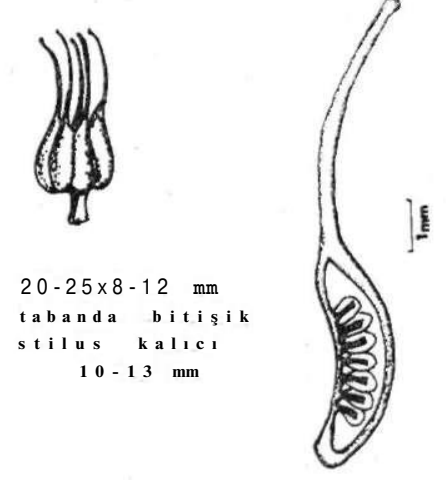

6 d a n f a z I a

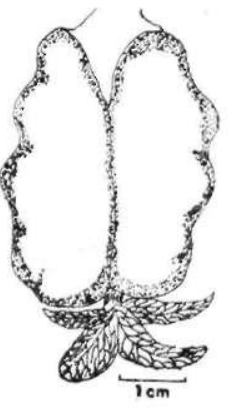

yeși l-s a $r$ I uclari eflatun $16-18 \mathrm{~mm}$

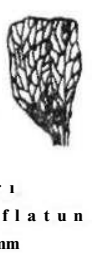
$50-70 \times 25-32 \mathrm{~mm}$ ortay a kadar stilus kalle $5-8 \mathrm{~mm}$

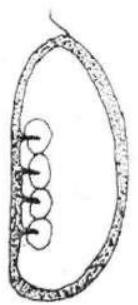

3 - 6 a de t $5-6 \mathrm{ma}$ 


\section{L İ T E R A T Ü R}

1- Martinis, Z., "Form and Development of Trichomes and Trichomoid Formations ön the Leaves of Several Helleborus species and their Significance for the Taxonomy of the Genus", Acta. Bot. Croat. (33) 93-110 (1974).

2- Trease, E. G., Evans, W. C, Pharmacognosy, 11 th Edition, Bailliere Tindall, London (1972).

3- Tutin, T. G., Heywood T. G., Burges, N. A., Moore, D. M., Valentine, D. H., Walters, S. M., Weeb, D. A., Flora Europea, 4, (1), Cambridge University Press, London (1976).

4- Baytop, A., Farmasötik Botanik, İ. Ü. Ecz. Fak. Yayınları (No: 25) Baha Matbaası, İstanbul (1972).

5- Baytop, T., Farmakognozi, II, İ. Ü. Yayınları (No: 1685) Ecz. Fak. (No: 12) Baha Matbaası, İstanbul 1971.

6- Karamanoğlu K., Farmasötik Botanik, A. Ü. Ecz. Fak. Yayınları (No: 24) A. Ü. Basımevi Ankara (1973).

7- Tanker, M., Tanker, N., Farmakognozi, I, Özışık Matbaası İstanbul (1973).

8- Davis, P.H., Flora of Turkey and the East Aegean Islands, I, Univ. Press. Edinburgh, (1965).

9- Güley, M., "Samsun ve Trabzon Bölgesi Tıbbi ve Zehirli Bitkilerden Başlıcalarının Farmakodinamik Etkileri ve Tedavideki Önemleri", A. U. Vet. Fak. Yayılarl (No: 49) 23-6 (1956).

10- Kantemir, İ., Temelli, E., "Helleborus orientalis Bitkisiyle Mukayeseli Araştırmalar", A. $\ddot{U}$. Tip Fak. Mec. XVI, (No: 1) Ankara Üniversitesi Basımevi (1963).

11 - Baytop, T., Malkoç, G., "Helleborus orientalis Lam. var. hirsutus (Schiffn) Hay. Kökleri Üzerinde Araştırmalar", İstanbul Ecz. Fak. Mec. I, 18 (1965). 